SECTION 32. Jurisprudence.

Irina Alexeevna Panina

Senior lecturer at the Department of constitutional and administrative law of the Volgograd branch of RANEPA, Deputy Head Volgograd Department of Rosprirodnadzor panin008@bk.ru

\title{
IMPLEMENTATION OF THE PUBLIC-PRIVATE PARTNERSHIP IN THE FIELD OF PRODUCTION AND CONSUMPTION WASTE IN CONSTITUENT AND MUNICIPAL ENTITIES OF THE RUSSIAN FEDERATION
}

\begin{abstract}
The article discusses the conceptual framework, and the legal and organizational aspects of the public-private partnership in the field of production and consumption waste in constituent and municipal entities of the Russian Federation as one of the methods to improve the effectiveness of the waste production and consumption management mechanism. The author focuses on the current state and the actual problems in the field of production and consumption waste, and the overall waste management strategy in the Russian Federation. The conclusions about the ways and means of addressing key issues was drawn.

Key words: Public-private partnership, production and consumption waste, municipal projects, economic substance of collsboration, waste management strategy, the natural resource potentials, growth rate of waste generation, environmental threat, waste minimization, State environmental supervision.

\section{РЕАЛИЗАЦИЯ ГОСУДАРСТВЕННО-ЧАСТНОГО ПАРТНЕРСТВА В СУБЬЕКТАХ РФ И МУНИЦИПАЛЬНЫХ ОБРАЗОВАНИЯХ В СФЕРЕ ОБРАЩЕНИЯ С ОТХОДАМИ ПРОИЗВОДСТВА И ПОТРЕБЛЕНИЯ}

Аннотация: В статье рассматриваются конщептуальные основы, а также правовые и организационные аспекты государственно-частного партнерства в субъектах Российской Федераџии и муниципальных образованиях в сфере обращения с отходами, как одного из методов повышения эффективности механизма управления сферой обращения с отходами производства и потребления. Автором сделан акиент на текущем состоянии и актуальных проблемах в области обращения с отходами производства и потребления, а также общей стратегии управления отходами в Российской Федераџии. Сделань выводы о путях и способах решения ключевых вопросов.

Ключевые слова: государственно-частное партнерство, отходы производства и потребления, муниципальные проекты, экономическая сущность взаимодействия, стратегия обращения с отходами, потенщиал природных ресурсов, темпы роста объемов образования отходов, экологическая угроза, минимизачия образования отходов, государственный экологический надзор.

Вступление человечества в эпоху глобализации обусловило и появление новых интернациональных угроз, важнейшей из которых является экологическая угроза. Действительно, когда нечем дышать и нет чистой воды для питья, многие экономические и политические проблемы теряют свою актуальность. Отсюда важнейшей задачей мирового сообщества, провозглашенной на трех последних мировых экологических саммитах (Стокгольм, 1972; Рио-де-Жанейро, 1992; Йоханнесбург, 2002) является обеспечение реализации права человека на благоприятную окружающую среду. Важнейшей составной частью данного блага является повышение эффективного обращения с отходами, как на национальном, так и международном уровне [1, с. 7]. В свою очередь, одним из путей 
решения данной проблемы является развитие системы государственно-частного партнерства. Как отмечалось в научной литературе, государственно-частное партнерство согласованно понимается как институциональное и организационное объединение между бизнесом и государством, цель которого - общественное осуществление значительных проектов (российских, также как и международных, касающихся как масштаба, так и помещения) в различных сферах. Как упорядочивает понятие, у такого объединения есть временный характер, потому что он создается в некий срок для осуществления конкретного проекта и после его осуществления он прекращает существование [3, с. 174].

Муниципалитеты встречаются постоянно с отсутствием бюджетных фондов, необходимых для осуществления тех или других муниципальных проектов. Частный сектор экономики обладает большим опытом, а также достаточными средствами, которые на взаимно выгодных условиях могут быть предоставленными муниципалитету для общественного осуществления значительных проектов [5, с. 71]. В этом случае сфера производства и обращения отходов прекращает быть рассматриваемой исключительно в качестве нагрузки для бюджета, а у бизнеса открываются новые горизонты [4, с. 19].

Экономически сущность взаимодействия в пределах государственно-частного партнерства имеет двойной характер: c одной стороны, государство приобретает возможность, используя способности, опыт и средства предпринимателей эффективно реализовывать значительные общественные проекты; с другой стороны, представители частного бизнеса получают дополнительный источник дохода. При осуществлении сотрудничества в рамках государственно-частного партнерства можно говорить о новом распределении средств и риска между государственными органами и частными лицами. Цель - оптимизация расходов публичных фондов и увеличение качества предоставления коммунальных услуг [9, с. 54].

Государственно-частное партнерство может принять несколько форм: различные контракты, где финансирование предоставляют частные компании; аренда (лизинг) в связи с передачей в аренду предпринимателям необходимого имущества; договор по секции производства; создание государственно-частных предприятий. В научной литературе проводится изучение данного вопроса, но в практической деятельности на последнюю форму российского государственно-частного партнерства обращено незаслуженно малое внимание, в то время как в иностранном юридическом опыте развитие такого партнерства показало самую развитую форму, большую перспективу и сложное взаимодействие [8, с. 567].

В экологической сфере (и в сфере обращения с отходами, в особенности) государственно-частное партнерство показывает традиционно высокую эффективность и важность, применяется к решению экологических проблем и организации средств охраны природы. В настоящее время в сфере обращения с отходами, как на региональном, так и на муниципальном уровне реализуется очень маленькое количество проектов частного бизнеса. Причиной является существование серии рисков осуществления деятельности, которыми частный инвестор не может руководить [7, с. 312].

Стратегия обращения с отходами производства и потребления в Российской Федерации (далее - Стратегия) представляет систему целей, заданий, направлений и пути его осуществления, которые должны реализовываться в федеральных законах и региональных юридических нормативах, нормативных актах муниципального уровня, федеральных программах со специальным назначением, региональных программах, проектах вложений и комплексов внепрограммных средств, направленных на создание и содержание активности отходоперерабатывающей промышленности.

Стратегия - основание для конструктивного взаимодействия между органами государственной власти и местного самоуправления, юридическими лицами, частными собственниками и населением, которых органы публичной власти информируют о своих 
решениях в сфере обращения с отходами производства и потребления для достижения целей, указанных в Стратегии.

Россия обладает огромным и различным по составу потенциалом природных средств, которые позволяют успешно развивать основные ветви экономики (топливноэнергетическая отрасль, черная и цветная металлургия, химическая и нефтехимическая отрасль, лесоперерабатывающая отрасль, строительство и т.д.). В то же время в периоды экономического подъема промышленность, комплексы транспорта, инфраструктуры постоянно увеличивают нагрузку, спровоцированную человеком на экологические системы. На сегодняшний день состояние в области обращения с отходами в Российской Федерации охарактеризовано ростом объемов образования и погребения отходов, которые получаются в процессе производства и потребления. Предусмотренные темпы роста их образования достигают 15-16 процентов в год, таким образом, значительно продвигая предусмотренные темпы роста ВВП [10, с. 17].

Самых больших объемов образования и захоронения отличаются отходы извлечения и обогащения минеральных средств. Несмотря на то, что они представляют собой натуральные материалы, добытые из природной среды, при взаимодействии с атмосферным воздухом и атмосферными осадками эти отходы могут загрязнять воздух, объекты воды, почву. Кроме того, объекты размещения отходов добычи и обогащения занимают огромные территории, которые только для эксплуатируемых объектов вычисляются в сотни тысячи гектар.

Среди отраслей, которые создают более чем 60 \% объема образования отходов, выделим металлургическое производство. Хранение на складе этих отходов на открытых маленьких площадях ведет к загрязнению объектов воды и почвы тяжелыми металлами. У основной части этих отходов есть потенциал как ресурса. Это показывают примеры, в которых очевидным способом много предприятий черной металлургии реализуют производство шлаковых отходов.

Разнообразием в номенклатуре и высшей степенью опасности охарактеризованы отходы химического производства. Основной способ исчезновения этих отходов погребение, которое создает реальную угрозу для состояния окружающей среды. Отходы агропромышленного комплекса привлечены к более активному экономическому обращению, но при их хранении на складе и захоронении осуществляются вредные выбросы в атмосферный воздух. При плохом состоянии объектов установки происходит отрицательное влияние на качество поверхностных и подземных вод, включая воды питьевое назначения. В стране до настоящего времени не решена проблема утилизации запрещенных пестицидов, в том числе испорченных агрохимикатов, которые представляют собой высокоопасные отходы. Согласно Государственному докладу «О состоянии и об охране окружающей среды Российской Федерации», их общее количество в предметах Российской Федерации в 2008 г. составило 23 тыс. тонн.

Черта текущего периода - рост заброшенных объектов размещения отходов, возникновение которых связано с ликвидацией или банкротством предприятий, которые они эксплуатируют. Часть объектов потеряла законных владельцев в течение реорганизации и приватизации предприятий, так как новые законные владельцы не приняли ответственность за ликвидацию ранее разрешенного загрязнения окружающей среды [2, с. 313-315]. Возможно оценивать реальные масштабы этой проблемы только после осуществления специальной работы по его раскрытию и инвентаризации. Указанная ситуация, сложившаяся в Российской Федерации в области обращения с отходами, сопровождается загрязнением окружающей среды, иррациональным использованием природных ресурсов, и создает реальную угрозу здоровью населения страны [6, с.7].

Мировой опыт показывает, что одним из направлений решения задач минимизации образования и погребения отходов, сокращающим отрицательное воздействие на окружающую среду и здоровье человека, является введение механизма эффективного 
государственного экологического надзора, позволяющего предотвращать загрязнения, и привлекать к ответственности производителей [2, с. 317].

\section{References:}

1. Анисимов А.П. Комментарий к Федеральному закону от 24 июня 1998 г. № 89-Ф3 «Об отходах производства и потребления» (постатейный) / А.П. Анисимов, А.В. Кодолова, А.Ю. Чикильдина // СПС «Консультант плюс», 2009 / дата обращения 2 июля 2014 г.

2. Анисимов А.П. Проблемы возмещения «прошлого» экологического ущерба [текст] / А.П. Анисимов // Государственно-правовая политика в сфере обеспечения национальной безопасности: всерос. науч.-практ. конференция (2012, Волгоград). Волгоград, 2012. - С.313-317.

3. Варнавский В. Государственно-частное партнерство в России: проблемы становления [текст] / В. Варнавский // Отечественные записки. - 2004. - № 6 (21). - С. 172-180.

4. Ротарь Ф. Государственно-частное партнерство как форма взаимодействия государственного и частного сектора экономики [текст] / Ф. Ротарь // Социальная политика и социальное партнерство. - 2011. - №7. - С. 16-23.

5. Шамбир В.Н. Государственно-частное партнерство как форма инвестирования приоритетных муниципальных проектов: автореферат диссертации на соискание ученой степени кандидата экономических наук по специальности 08.00.01 [текст] / В.Н. Шамбир. - Москва, 2010. - 150 с.

6. Салтыков А.И. Проблемы реализации органами местного самоуправления полномочий в сфере обращения с отходами производства и потребления [текст] / А.И. Салтыков // Аналитический вестник Совета Федерации ФС РФ. - 2010. - №5 (391).

7. Игнатюк, Н.А. Муниципальное право [текст] / Н.А. Игнатюк, А.В. Павлушкин. - М.: Юстицинформ, 2007. - 312 с.

8. Проблемы общей теории права и государства: Учебник для вузов / Под общ. ред. В.С. Нерсесянца. - М.,1999. - С. 567.

9. Анисимов А.П., Коростелева М.В. Правовое регулирование экономических основ местного самоуправления в России: дискуссионные вопросы // Новая правовая мысль. - 2014. - № 1. - C.50-55.

10. Салтыков А.И. Проблемы реализации органами местного самоуправления полномочий в сфере обращения с отходами производства и потребления [текст] / А.И. Салтыков // Аналитический вестник Совета Федерации ФС РФ. - 2010. - №5 (391). 